Research Article

\title{
Strengthening of Steel Columns under Load: Torsional-Flexural Buckling
}

\author{
Martin Vild and Miroslav Bajer \\ Faculty of Civil Engineering, Institute of Metal and Timber Structures, Brno University of Technology, \\ Veveři 331/95, 60200 Brno, Czech Republic
}

Correspondence should be addressed to Martin Vild; vild.m@fce.vutbr.cz

Received 8 June 2016; Accepted 18 September 2016

Academic Editor: Ana S. Guimarães

Copyright @ 2016 M. Vild and M. Bajer. This is an open access article distributed under the Creative Commons Attribution License, which permits unrestricted use, distribution, and reproduction in any medium, provided the original work is properly cited.

The paper presents experimental and numerical research into the strengthening of steel columns under load using welded plates. So far, the experimental research in this field has been limited mostly to flexural buckling of columns and the preload had low effect on the column load resistance. This paper focuses on the local buckling and torsional-flexural buckling of columns. Three sets of three columns each were tested. Two sets corresponding to the base section (D) and strengthened section (E) were tested without preloading and were used for comparison. Columns from set (F) were first preloaded to the load corresponding to the half of the load resistance of the base section (D). Then the columns were strengthened and after they cooled, they were loaded to failure. The columns strengthened under load (F) had similar average resistance as the columns welded without preloading (E), meaning the preload affects even members susceptible to local buckling and torsional-flexural buckling only slightly. This is the same behaviour as of the tested columns from previous research into flexural buckling. The study includes results gained from finite element models of the problem created in ANSYS software. The results obtained from the experiments and numerical simulations were compared.

\section{Introduction}

Strengthening is a type of retrofit works, in which a material is added to a base cross-section in order to transfer additional load. The use of welded plates to strengthen steel members is a common practice because it is fast and cheap. Unloading the structure before strengthening may often be almost unfeasible or economically inconvenient, in which case strengthening under load is carried out (for case study examples see [1-3]). Although there are several rules of thumb, current normative documents do not refer to this problem and no reliable analytical solution has been developed to date [4]. In most of the experiments detailed in literature (e.g., [57]), the load resistance of columns strengthened under load was very similar to that of reference columns strengthened without preloading. However, there is no consensus among researchers. Some (Brown [8], Ricker [9], Spal [10], and Unterweger [11]) believe that load resistance is decreased by preloading, others (Tall [12], O'Sullivan [5], Tide [13], Wu and
Grondin [14], and Bhowmick and Grondin [15]) claim that well designed and conducted column strengthening under load does not decrease its load resistance.

The paper presents experimental and numerical research into the strengthening of columns under load using welded plates. Experimental research of other investigators (e.g., [6, $7,16]$ ) was focused on flexural buckling of columns. Also other works of authors investigated flexural buckling of wide flange columns strengthened under load with intermittent welds [17]. All the experimental research into flexural buckling showed that the preload had low effect on the load resistance of the column strengthened under load. Therefore, columns susceptible to local and torsional-flexural buckling were selected. Additionally, the theoretical axis of loading did not pass the column centre of gravity which caused a bending moment. The experiments were conducted at the laboratory of the Institute of Metal and Timber Structures at Brno University of Technology in April 2015. The purpose of this paper and the presented experiments is to contribute 


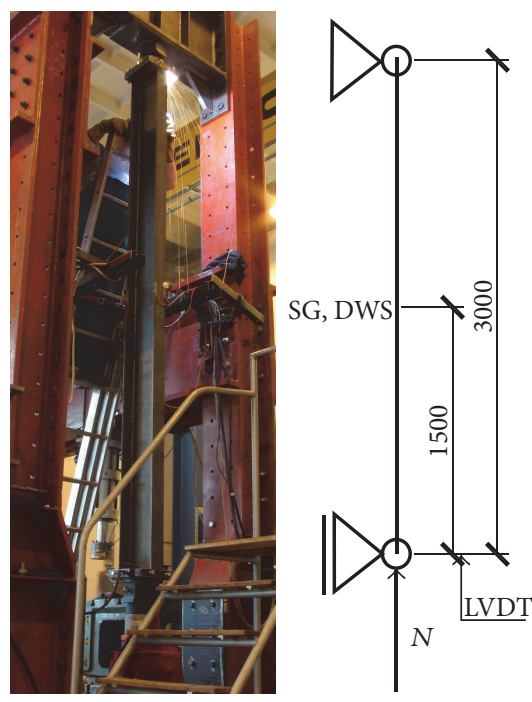

FIGURE 1: Column specimen strengthened under load in the test setup.

to the existing body of knowledge concerning strengthening under load that aims to make retrofit design both safe and economical.

\section{Materials and Methods}

Three sets of columns were selected for the research. The experimental sets of columns comprise three columns each. Set (D) includes columns labelled D1, D2 and D3, set (E) columns E1, E2 and E3, and set (F) columns F1, F2 and F3. Numerical models of columns are labelled D, E and F. The columns were subjected to a compressive force (see Figure 1). The axis of loading passing through axis $y^{\prime}$ did not pass the centre of gravity (intersection of axes $y$ and $z$ ) which caused additional bending moment. The cross-sections are presented in Figure 2. All columns were welded with continuous welds; the throat thickness of which was $4 \mathrm{~mm}$. Set (D) included columns with a T-shaped cross-section welded from the flange with the dimensions $140 \times 8.1 \mathrm{~mm}$ and from the web with the dimensions $200 \times 5.4 \mathrm{~mm}$. The columns from set (D) were class 4 according to the classification of crosssections in EN 1993-1-1 [18]. Set (E) comprised columns with a monosymmetric I-shaped cross-section. The flanges had the dimensions $140 \times 8.1 \mathrm{~mm}$ and $80 \times 7.9 \mathrm{~mm}$, and the web was $200 \times 5.4 \mathrm{~mm}$ in size. Sets (D) and (E) were necessary for the comparison of behaviour and resistance. Set (F) contained columns with a T-shaped cross-section with the same dimensions as the columns in set (D). The columns from set (F) were first loaded to $70 \mathrm{kN}$ and then strengthened under this load with a second flange. The preload magnitude was chosen as the half of the average experimental load resistance of set (D). The preload ratio (ratio of the preload magnitude and the base section load resistance) 0.5 is considered in Czech technical recommendations [19] as the maximum limit value for strengthening under load. The resulting cross-section was the same as that of the columns from set (E). The columns from sets $(\mathrm{E})$ and $(\mathrm{F})$ were class 3 .

Buckling resistance of investigated beam-columns was determined using Cl. 6.3.4 general method for lateral and lateral torsional buckling of structural components in Eurocode 1993-1-1 [18]. Values of $\alpha_{\text {ult }, k}$ and $\alpha_{\text {cr,op }}$ were determined numerically using average measured thicknesses of plates and average yield stress determined from coupon tests.

2.1. Experimental Research. Each set comprised three columns (labelled 1,2, and 3) selected for use in experimental research. All columns were $3 \mathrm{~m}$ long and loaded by loading cylinder. The load was transferred through knife-edge bearings (see Figure 3), which provided pinned boundary conditions perpendicular to stronger axis $y^{\prime}$ and fixed perpendicular to weaker axis $z$. The load acted on axis $y^{\prime}$ which does not align with the axis $y$ passing through the centre of gravity. The distances between axes $y^{\prime}$ and $y$ are $53.5 \mathrm{~mm}$ and $18.4 \mathrm{~mm}$ in cases of base section and strengthened section, respectively. Hence, the axial force causes also bending moment. Both sets (D) and (E) were loaded monotonically until collapse occurred. The columns from set $(\mathrm{F})$ were first inserted into the loading set-up and loaded to $70 \mathrm{kN}$. The force was manually held roughly constant $( \pm 5 \mathrm{kN})$ while the second flange with the dimensions $80 \times 7.9 \mathrm{~mm}$ was welded to the web under the load. The shielded metal arc welding method with electrode wire thickness $2.3 \mathrm{~mm}$ was used. The force rose by around $1 \mathrm{kN}$ per $12 \mathrm{~s}$ while the steel was being heated by the welding process and dropped at a similar rate while the process was paused and the column cooled. The load and column elongation and shortening of specimen F3 can be seen in Figure 4. The temperature of the column was monitored with a handheld infrared thermometer. After the welding process was finished and the specimen had cooled, columns F1 and F2 were unloaded to $10 \mathrm{kN}$ to determine the change of initial imperfections as suggested by Unterweger [11] and then loaded to failure. Column F3 was loaded to failure without unloading.

Tension coupon tests were conducted to determine steel mechanical properties. Three coupons were machined from webs, three from longer flanges, and three from shorter flanges. The precise thickness of the plates was measured with callipers at several spots and the average value was used for numerical analysis. 1-LY11/6/350 strain gauges (SG) were used (see Figure 2) to measure the strain, which was recalculated into stress using the true stress-strain diagram obtained from the coupon tests. The vertical displacement and force at the bottom of the column and the horizontal deflection and strains at midheight were measured for all specimens. A Southwell plot [20] was used to determine the initial imperfections.

2.2. Numerical Modelling. Numerical simulations were performed to complement the values which had not been measured in the experiment. ANSYS software [21] was used for finite element analyses. The temperature load from thermal analyses was used to model the effects of the continuous weld with a throat thickness of $4 \mathrm{~mm}$. The temperature load corresponded with the deformations measured in these 
(D)

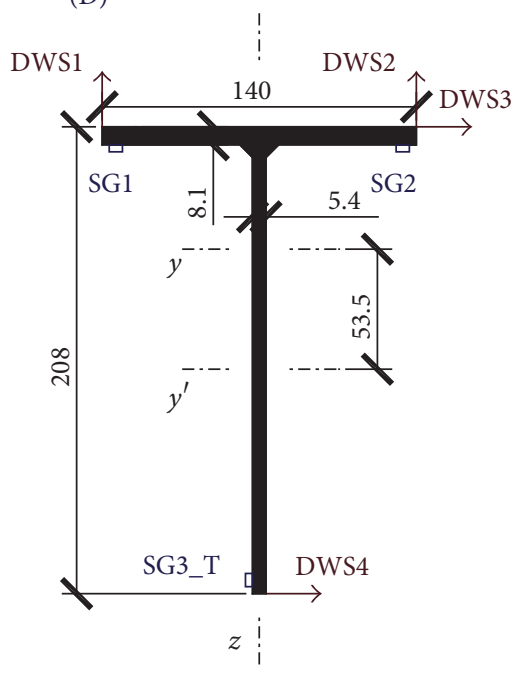

(E)

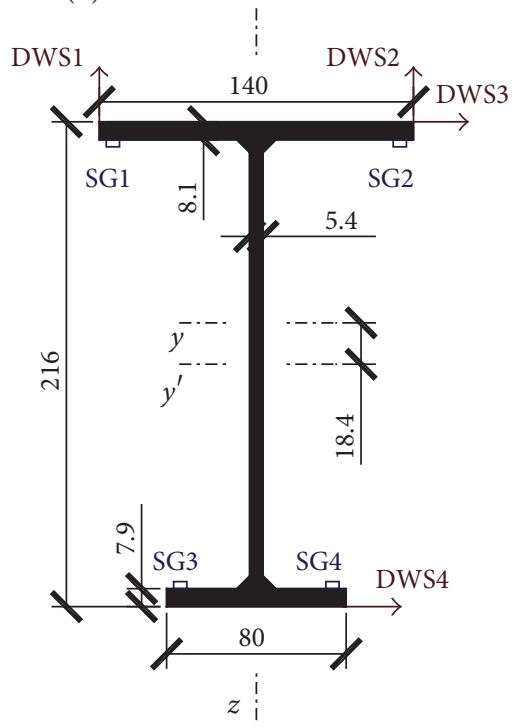

(F)



FIGURE 2: Column sets with dimensions, axes, strain gauge (SG) positions, and draw wire sensors (DWS) positions.


FIGURE 3: Knife-edge boundary conditions.

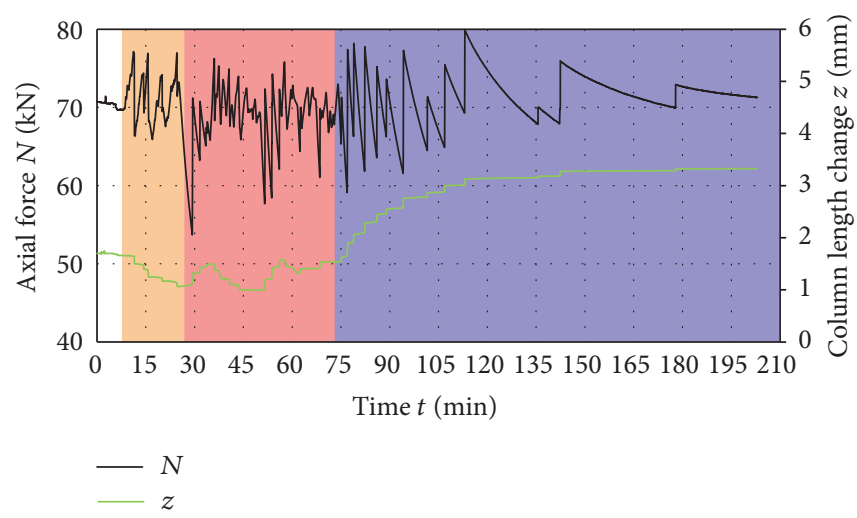

FIGURE 4: Axial force and column length changes during the spot welding (orange background colour), welding process (red colour), and cooling (blue colour). 
experiments and similar experiment performed by authors [22] and the longitudinal stresses available in the literature (e.g., [23-25]). The residual stress of bare plates was neglected. The SHELL 181 element type was used for all plates. It is a fournode structural shell element with six degrees of freedom at each node which is well suited for large strain nonlinear applications [21]. The mesh had to be relatively dense (element size $4 \times 10 \mathrm{~mm}$ ) due to high stress gradients caused by welding simulation. Mapped mesh was used all over the column and welds; the degenerate triangular elements were used only on few plates of knife-edge bearings which were modelled with several plates (see Figure 3). The material model of the knifeedge bearings was elastic (modulus of elasticity $E=210 \mathrm{GPa}$ ) and the material model of the plates was multilinear isotropic with the average true stress-strain diagram obtained from the coupon tests. The columns in the numerical analyses, labelled D, E, and F, correspond to sets of specimens (D), (E), and (F) used in the experimental research.

The column strengthened under load F was modelled using the following procedure. First, the ideal geometry was created. Pinned boundary conditions around the axis $y^{\prime}$ and node coupling in longitudinal direction $x$ were used at the position of the knife-edge bearings. Then, the model was updated with imperfections using Block Lanczos Eigen Buckling analyses. The elements of the strengthening plate and fillet welds were deactivated and the base column with a T-shaped cross-section was updated with the first mode of Eigen Buckling analysis. This mode corresponded to the local buckling of the web and caused web undulation. The maximum deflection was chosen as $1 \mathrm{~mm}$, which corresponded to $1 / 200$ of the web width. The strengthening elements were then activated and another Eigen Buckling analysis was performed. The first mode, corresponding to global torsionalflexural buckling, was selected with a maximum deflection of $3.75 \mathrm{~mm}$, which was equal to $1 / 800$ of the column length that is the limit geometrical tolerance stated in EN 1090-2 [26] and roughly coincided with the average results of the Southwell plot. Additionally, other three modes were added with decreasing amplitude $(3.75 \mathrm{~mm}, 1.875 \mathrm{~mm}, 0.938 \mathrm{~mm}$, and $0.469 \mathrm{~mm}$ for the first, second, third, and fourth mode, resp.). The elements were then switched to SHELL 131 and two thermal analyses were conducted. The first was for the residual stresses distribution of the base welded T-shaped cross-section, and the second was for deflections and residual stresses caused by the welding of the strengthening flange under load (see Figure 9). After this, the elements were changed to structural again and five consecutive static analyses were performed. First, the elements of the strengthening plate were deactivated and the residual stresses for the base Tshaped cross-section were implemented. Second, the column was loaded to $70 \mathrm{kN}$. Third, the elements of the strengthening plate were reactivated and residual stresses and deflections caused by the welding process were implemented. Fourth, the column was unloaded to determine the change in the initial imperfections of the column strengthened under load. Finally, the column was loaded with force until the solver stopped converging, meaning collapse had been reached.

For the purpose of comparison, the models of columns $\mathrm{D}$ and $\mathrm{E}$ were also created using a similar procedure. The

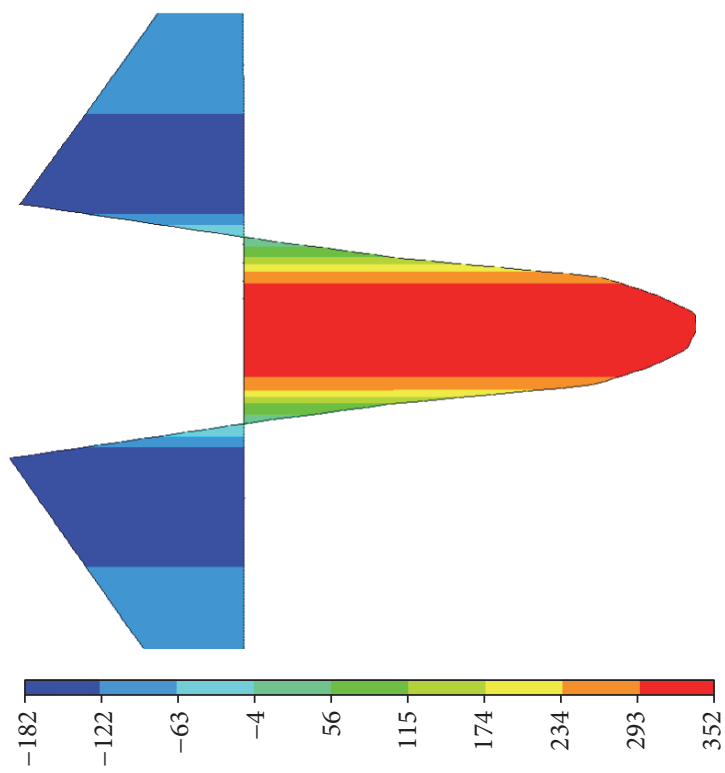

FIgURE 5: Stress distribution in longitudinal direction $\sigma_{x}[\mathrm{MPa}]$ caused by welding in longer flange used in finite element analysis.

geometry of columns D and E updated the same imperfections as column F. The same program and similar procedure were used by Liu and Gannon [27, 28] and Wang et al. [29] in their recent work on beams strengthened under load.

The effect of residual stress was investigated in greater detail because it is the source of unknown variables. The temperature load that was determined to correspond to the measured deformations of specimens (throat thickness $4 \mathrm{~mm}$, area of the weld $A_{w}=32 \mathrm{~mm}^{2}$; see Figures 5 and 9) and then temperature load higher by $33 \%$ and lower by $33 \%$ was applied to the models of columns D, E, and F. These temperature loads are expected to correspond to the weld with throat thickness $3.3 \mathrm{~mm}$ (area of the weld $A_{w}=$ $21 \mathrm{~mm}^{2}$ ) and $4.6 \mathrm{~mm}$ (area of the weld $A_{w}=43 \mathrm{~mm}^{2}$ ) for temperature load 33\% lower and 33\% higher, respectively. A little difference in throat thickness leads to a relatively big difference in the area of the weld. Other variables are the travel speed of the welding arc, number and length of pauses, and so forth. These variables are impossible to account for in field welding. The results of this parametric study are described further.

\section{Results and Discussion}

3.1. Experimental Research. The results of mechanical properties were averaged. Young's modulus of elasticity, yield strength, and ultimate strength were $210 \mathrm{GPa}, 316 \pm 5 \mathrm{MPa}$ $(\bar{\rho}=1.57 \%)$, and $454 \pm 5 \mathrm{MPa}(\bar{\rho}=1.01 \%)$, respectively.

Stresses recalculated from strain gauges and deflections obtained from draw wire sensors (DWS) at the moment of collapse are plotted in Figure 6; graphs of deflections dependent on the axial force are shown in Figure 8. Note that the deflections caused by welding at the load $70 \mathrm{kN}$ are included. The specimens from sets (E) and (F) failed via torsional-flexural buckling and the specimens from set (D) 

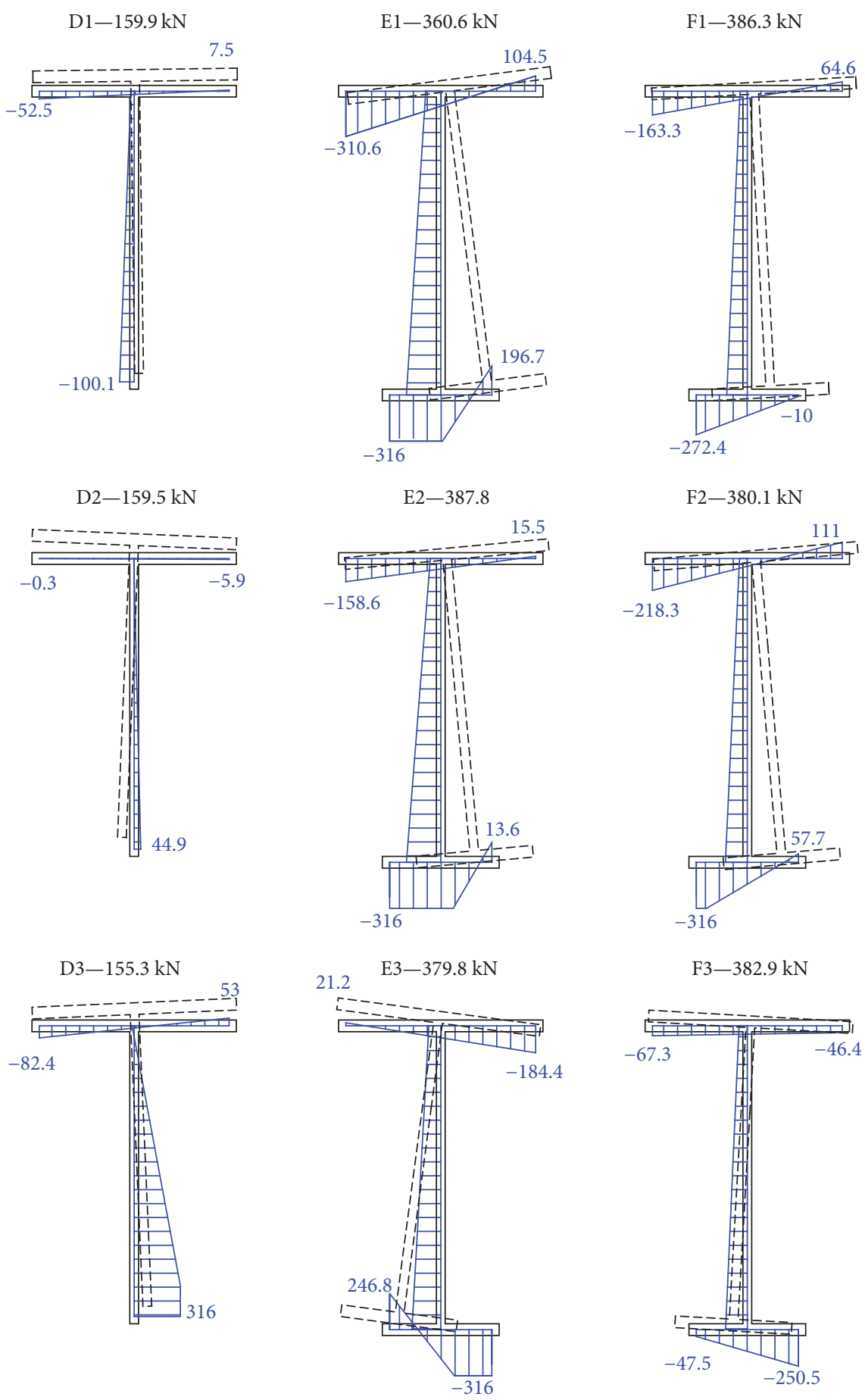

FIGURE 6: Experimental results at the moment of collapse: load resistance, stresses recalculated from strain gauges [MPa], and deflections.

failed via local buckling of the web, as expected (see Figure 7). In the case of specimens from set (D), strain gauges and draw wire sensors were positioned at midheight and the wave of local buckling occurred at a different location. This is the reason for big differences in the direction of axis $y$, rotation $\theta$, and stress recalculated from strain gauges.

The welding process caused deformation of the flanges. The weld caused shrinkage and the flanges inclined by approximately $3^{\circ}$ in the direction towards the web. The average stress on the flange of the base T-shaped crosssection (the average of SG1 and SG2) at $70 \mathrm{kN}$ of load was only $-13.4 \mathrm{MPa}$ (compression). The stress after the welding process even switched into tension, to an average value of 13.9 $\mathrm{MPa}$ (tension). The stress on the web of the base Tshaped cross-section (SG3) was $-85.9 \mathrm{MPa}$, which is still a low value compared to the yield stress. Unfortunately, the 


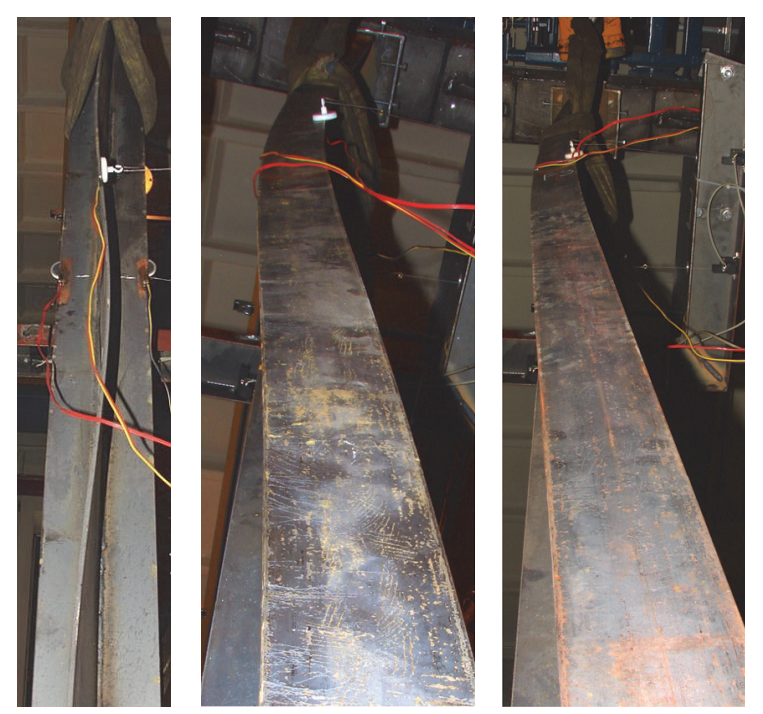

FIGURE 7: Local buckling of column D2 (before collapse occurred) and torsional-flexural buckling of columns E3 and F3 (after collapse).

welding process near SG3_T destroyed the strain gauge but the weld clearly caused shrinkage. The specimens from set (F) were deflected at midheight by welding by an average value of $-8.63 \mathrm{~mm}$ in the direction of axis $z$. This value corresponds well with the calculation by Blodgett [24] and Huenersen et al. [25], $-7.59 \mathrm{~mm}$ and $-9.03 \mathrm{~mm}$, respectively.

The average load resistance of set (D) was $157 \mathrm{kN}$, which is much larger value than the one calculated from EC 3 [18] $76 \mathrm{kN}$. This issue is known and is handled by researchers, for example, [30]. The average load resistance of set (E) was $376 \mathrm{kN}$ and for set $(\mathrm{F})$ it was $383 \mathrm{kN}$; both values slightly exceeded resistance calculated according to EC $3-342 \mathrm{kN}$. In the case of these six specimens, the average resistance of the column strengthened under load (F) was similar and even slightly increased compared to the column with an Ishaped cross-section welded without preloading (E). This could be explained by the effect of residual stresses and deflections caused by welding, which caused the tension in the most compressed base section flange. Furthermore, the stress in the shorter flange, which is decisive for the column resistance, is slightly lower at the moment of collapse in the case of set (F) than in the case of set (E) (see Figure 6). In the case of specimens from set (E) at $70 \mathrm{kN}$, the average stress on the short flange (average of SG3 and SG4 which were glued after welding and therefore they did not take into account residual stresses) was -29.4 MPa. Using a combination of numerical (only to determine residual stress) and experimental results, it seems that the shorter flange of specimens from set (F) started to yield in average at $21 \mathrm{kN}$ higher load than in the case of specimens from set (E). This behaviour and a slight increase in load resistance were also observed in previous experimental research by the authors [22] and in the literature, for example, by Nagaraja Rao and Tall [6]. However, it seems that specimen E1 had higher initial nonintended eccentricity in supports which resulted in the
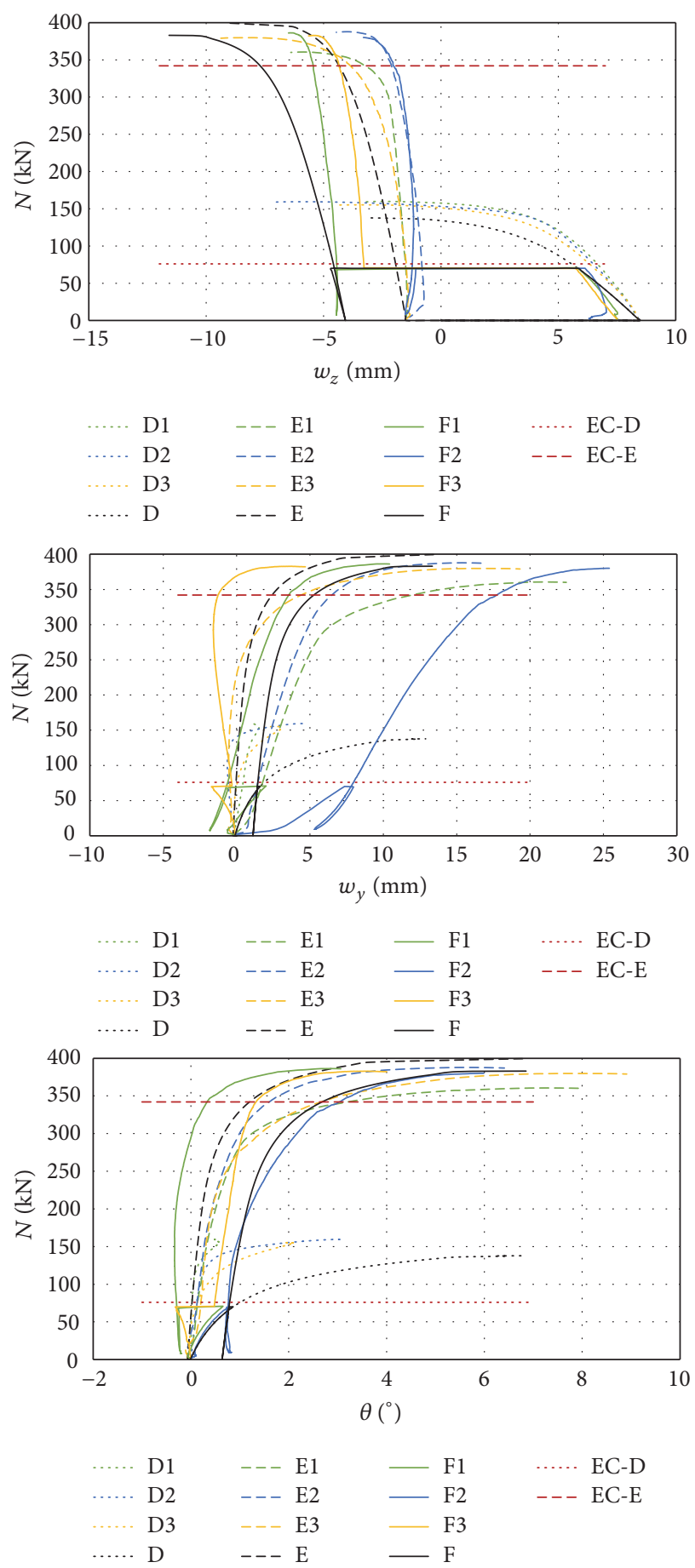

FIGURE 8: Graphs of deflections in the middle of the column in the direction of principal axes $y$ and $z$ and rotation $\theta$, deflections caused by welding are included; numerical results are in black; calculation according to EC 3 is in red.

lower load resistance. Additionally, column E1 was delivered slightly damaged by the supplier.

The unloading and loading load-displacement curves of columns F1 and F2 followed the same path and the load resistances of both specimens were the same as of column F3. Therefore, it is presumed the unloading to $10 \mathrm{kN}$ did not 


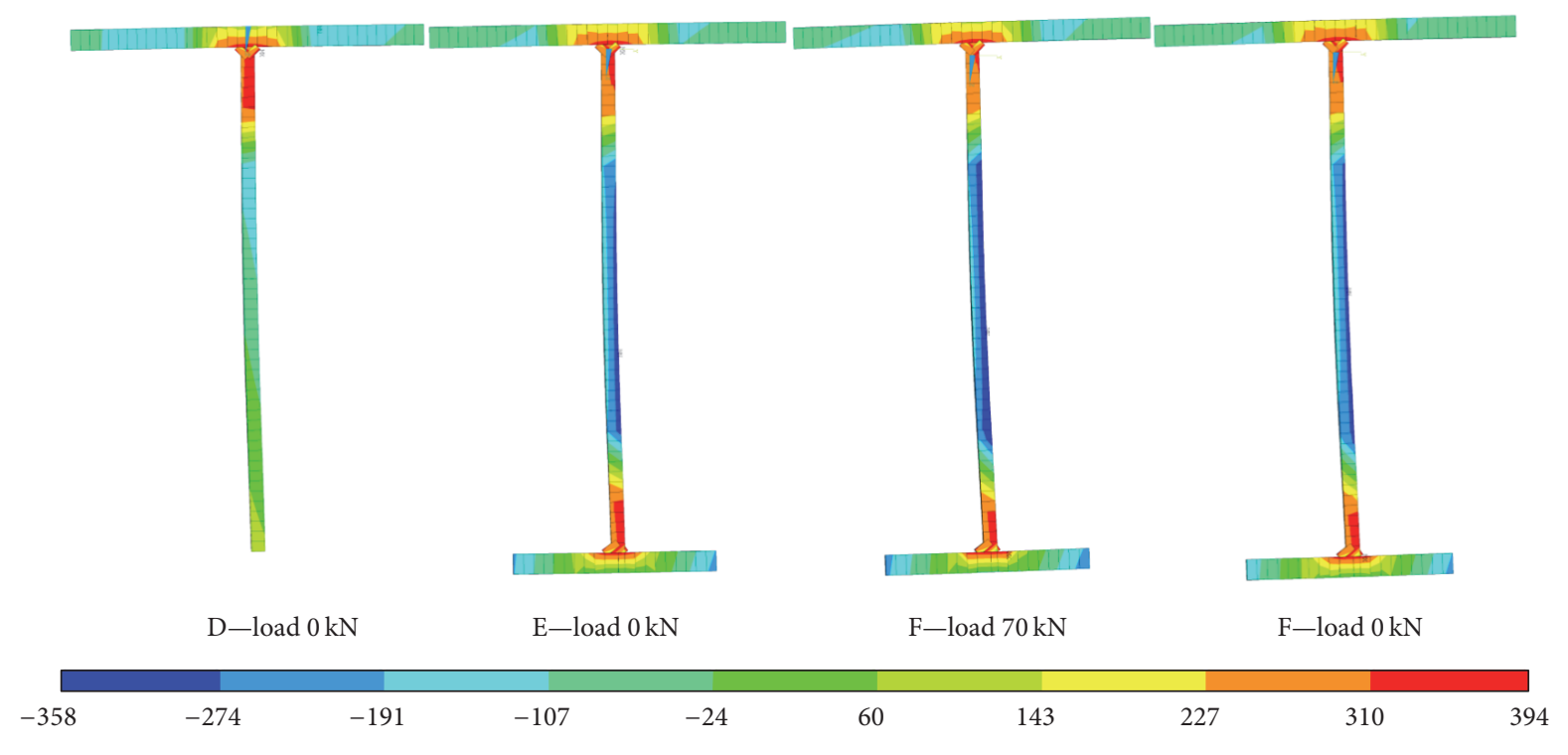

FIGURE 9: Residual stresses in the longitudinal direction $\sigma_{x}[\mathrm{MPa}]$ caused by welding at midheight.

affect the column behaviour. From the graphs in Figure 8, it can be seen that the strengthened column is stiffer and its load-displacement curve is more vertical. This confirms the theory of increased imperfection by Unterweger [11]. However, the welding process caused predictable deflection in the direction of axis $z$ which was much more serious and random deflection in the direction of axis $y$ and rotation $\theta$ which were of the similar magnitude as the increased imperfection.

3.2. Numerical Modelling. The goal was to achieve similar distortion and stress distribution as described in Section 3.1. Then, values which were unclear and hard to measure in the experiment could be read from the finite element models. The results of deflections are included in Figure 8 for comparison with the experimental results. The numerical results correspond closely to those from the experiment. Differences may be accounted for by the different shapes of the initial imperfections. A large difference only appeared in the case of set (D), which failed via local buckling. Unlike in the case of the finite element analysis, the decisive buckling wave that occurred during the experiment did not occur at the midheight where the measurements were taken and therefore only the deflections in the direction of axis $z$ are comparable. The deflections of column $\mathrm{F}$ during the loading were slightly higher than those of column E. This suggests that the assumption made by Unterweger [11] that there are higher initial imperfections in the member strengthened under load is correct. However, the experimental results do not show clear pattern due to the unpredictable stresses and deflections caused by welding.

Residual stresses caused by welding are shown in Figure 9. Column F had lower compression stress than column E in the shorter strengthening flange where the most stressed fibres were located when the column later failed via buckling. This might be one of the reasons why the columns

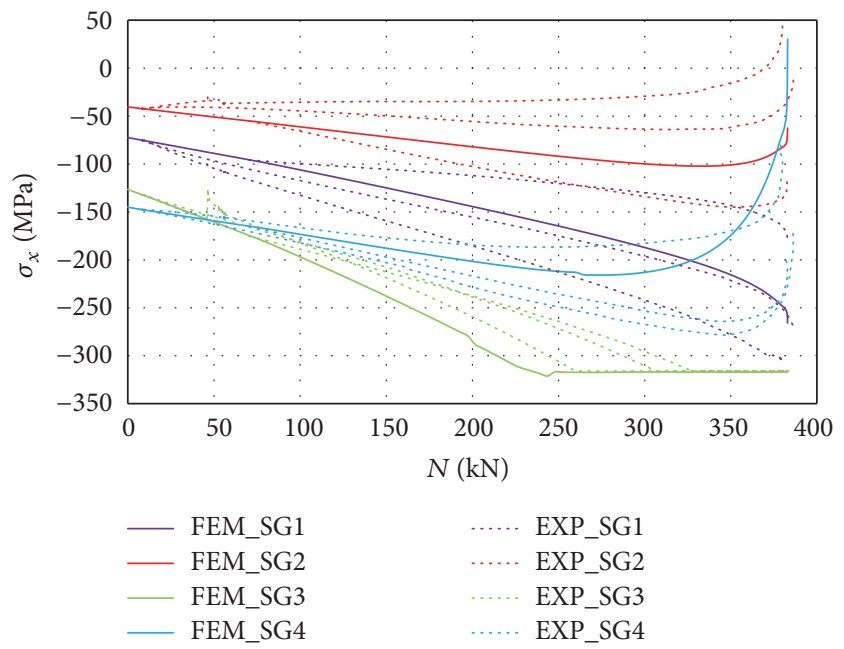

FIGURE 10: Longitudinal stresses on strain gauges during loading, comparison of numerical model and experimental results.

strengthened under load (F) had a slightly higher average load resistance than the regular columns (E) tested in the experiment. Longitudinal stresses $\sigma_{x}$ in the position of the strain gauges are compared with the experimental results in Figure 10. The stresses from the experiment were recalculated from measurements obtained from the strain gauges, which unfortunately were not glued to the plain plates, so they did not reflect the residual stresses. For this reason, the origins of experimental stresses (dotted lines) were set to the stresses from the numerical model at zero load. Figure 11 shows the stresses in the longitudinal direction at the moment of collapse. The stress distribution of columns $\mathrm{E}$ and $\mathrm{F}$ is very similar, with a significant portion of the cross-section passing the yield point in both cases. The load resistance of columns $\mathrm{D}, \mathrm{E}$, and $\mathrm{F}$ was $137.8 \mathrm{kN}, 399.4 \mathrm{kN}$, and $383.0 \mathrm{kN}$, respectively. 


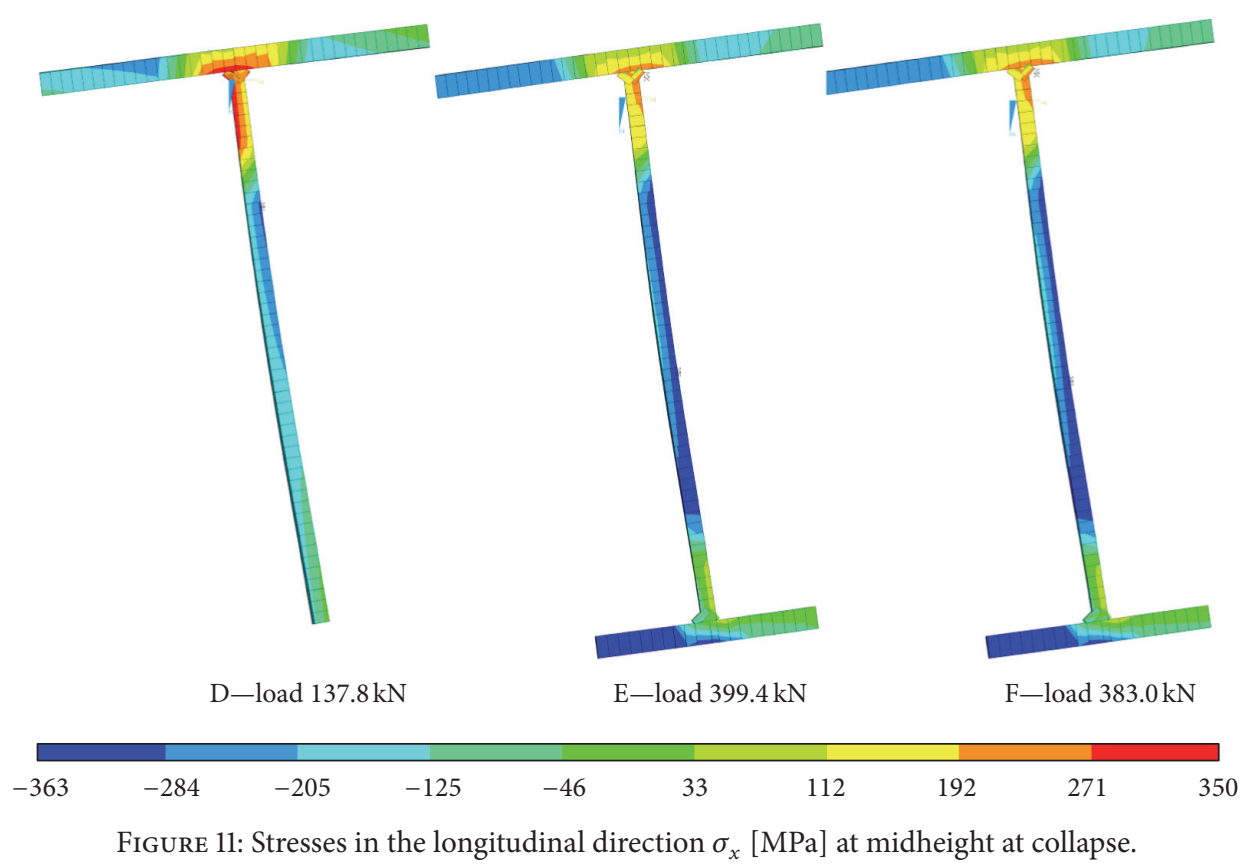

The member strengthened under load $\mathrm{F}$ and under no load E had nearly the same load resistance. The slight increase in load resistance for the set of columns strengthened under load $(F)$ measured in the experiment was therefore not confirmed by these finite element analyses. This suggests that this increase could be caused by smaller initial imperfections of specimens from set (F), the slightly damaged specimen E1, and possible different quality of the strengthening weld, as discussed further.

The results of the parametric study concerning the temperature load causing residual stress distribution are summarised in Table 1 . The temperature load corresponding to the average measured deformations of the specimens, the decreased temperature load, and the increased temperature load are labelled exp, $0.67 \times$ exp, and $1.33 \times$ exp, respectively. In the case of column $\mathrm{D}$ with the T-shaped cross-section, the load resistance increased with increasing temperature load. This can be explained by the higher deflection in the direction of axis $z$ which decreased the distance between the point of load application and the centre of gravity in the midheight which led to smaller bending moment. In the cases of columns E and F, the load resistance slightly decreased with increasing temperature load. The difference in deflections caused by welding, while big on its own, is small if effects of both welds at longer flange and shorter flange are summed up. The decrease in load resistance can be attributed to the higher compressive residual stress. The decrease in load resistance of the highest and lowest applied temperature load was only $8 \%$ but it can be one of the factors contributing to the difference between results of specimens in each set of experimental study and also the difference between numerical models and averages of experimental study. The welder performed welding operations of specimens from sets (D) and (E) and the welds at the longer flange of specimens (F) comfortably on the bench in a horizontal position. The strengthening fillet
TABLE 1: Results of parametric study: load resistance $N_{b, R}$, deflection in the direction of axis $z$ caused by the fillet weld at longer flange $w_{z, \mathrm{~T}}$ and at shorter flange $w_{z, \mathrm{I}}$

\begin{tabular}{lcccc}
\hline Column & Temperature load & $N_{b, R}[\mathrm{kN}]$ & $w_{z, \mathrm{~T}}[\mathrm{~mm}]$ & $w_{z, \mathrm{I}}[\mathrm{mm}]$ \\
\hline \multirow{2}{*}{$0.67 \times \exp$} & 134 & 6.3 & \\
& $\exp$ & 138 & 8.5 & \\
& $1.33 \times \exp$ & 140 & 10.3 & \\
\hline \multirow{2}{*}{$\mathrm{E}$} & $0.67 \times \exp$ & 420 & 6.3 & -7.2 \\
& $\exp$ & 399 & 8.5 & -9.9 \\
& $1.33 \times \exp$ & 387 & 10.3 & -12.4 \\
\hline \multirow{2}{*}{$\mathrm{F}$} & $0.67 \times \exp$ & 405 & 6.3 & -7.4 \\
& $\exp$ & 383 & 8.5 & -10.5 \\
& $1.33 \times \exp$ & 374 & 10.3 & -13.4 \\
\hline
\end{tabular}

welds at the shorter flange of specimens (F) were performed in a vertical position, the upper parts from a ladder. Thus, the quality of welds, travel speed of the welding arc, and so forth were affected.

\section{Conclusion}

The experiments on slender columns susceptible to local and global buckling proved that the method of strengthening Tshaped columns with a second flange under preload magnitude up to $50 \%$ of the base section's buckling resistance is safe and feasible. These six experiments support the claim that the load resistance of a column strengthened under load is nearly the same as that of a column welded without preloading. The numerical simulation was managed to determine values that had not been measured in the experiment. The following 
conclusions can be drawn from the experiments and research involving numerical models:

(1) The force changes rapidly during the shielded metal arc welding process with thick electrode core wire. Temperature changes must be carefully monitored and stress changes considered especially if the column is less stiff than surrounding structural components. Use of thin electrode core wire or intermittent welds could reduce these changes.

(2) The residual stresses and deformations caused by welding are often much higher than the stresses caused by preloading. Especially in cases with slender base sections, the stresses during axial loading rise slowly with increasing load but plummet at the most stressed fibres in the cross-section when the load on the column is nearing its critical load. Therefore, with preload magnitudes up to $50 \%$ of the base section's load resistance, the buckling of the base section (both local and global) hardly affects the load resistance of the strengthened section and strengthening plates can prevent further local buckling.

(3) Welding causes shrinkage and tensional residual stresses near the weld. If the strengthening method is designed so that the position of the welds is near the most compressed fibres or causes deformations which have a positive influence, the welds can increase buckling resistance.

(4) Similarly, if possible, strengthening plates should be positioned outside the base cross-section in order to increase the moment of inertia. In the case of columns strengthened under load, these plates reach the yield point later, thus increasing buckling resistance.

The validated numerical model will find application in the behavioural analysis of members strengthened under load in future research in this area. Such research is currently in progress, and other experiments have already been planned to verify the above-mentioned conclusions.

\section{Competing Interests}

The authors declare that there is no conflict of interests regarding the publication of this paper.

\section{Acknowledgments}

The financial support of Project no. LO1408 "AdMaS UPAdvanced Materials, Structures and Technologies," supported by the Ministry of Education, Youth and Sports under "National Sustainability Programme I" is gratefully acknowledged.

\section{References}

[1] H. A. Gordy, "South Shore Plaza," Modern Steel Construction, AISC, 1997.

[2] S. Punch and S. S. Wall, "Constant growth," Modern Steel Construction, AISC, 1994.
[3] K. Horikawa and H. Suzuki, "Studies on repair welding in Japan," Transactions of JWRI, pp. 175-183, 1985.

[4] R. L. Brockenbrough, "AISC rehabilitation and retrofit guide: a reference for historic shapes and specifications," APT Bulletin, vol. 34, no. 1, p. 53, 2003.

[5] T. P. O'Sullivan, "Strengthening of steel structures under load," Proceedings of the Institution of Civil Engineers, vol. 2, no. 1, pp. 76-95, 1953.

[6] N. R. Nagaraja Rao and L. Tall, "Columns reinforced under load," Welding Journal, vol. 42, p. 54, 1963.

[7] H. Marzouk and S. Mohan, "Strengthening of wide-flange columns under load," Canadian Journal of Civil Engineering, vol. 17, no. 5, pp. 835-843, 1990.

[8] J. H. Brown, "Reinforcing loaded steel compression members," AISC Engineering Journal, pp. 161-168, 1988.

[9] D. T. Ricker, "Field welding to existing steel structures," AISC Engineering Journal, pp. 1-16, 1988.

[10] L. Spal, Rekonstrukce Ocelových Konstrukcí, STNL, Prague, Czechoslovakia, 1968.

[11] H. Unterweger, "Ultimate load capacity of columns strengthened under preload," Advances in Steel Structures, vol. 1, pp. 117124, 1999.

[12] L. Tall, "Reinforcement of steel columns," AISC Engineering Journal, pp. 33-39, 1989.

[13] R. H. R. Tide, "Reinforcing steel members and the effects of welding," AISC Engineering Journal, vol. 27, no. 4, pp. 129-131, 1991.

[14] Z. Wu and G. Y. Grondin, "Behaviour of steel columns reinforced with welded steel plates," Structural Engineers Report 250, University of Alberta, Edmonton, Canada, 2002.

[15] A. K. Bhowmick and G. Y. Grondin, "Limit state design of steel columns reinforced with welded steel plates," Engineering Structures, vol. 114, pp. 48-60, 2016.

[16] V. M. Kolesnikov, "O normách po rasčotu stalnych konstrukcij, usiljennych pod nagruzkoj," Promyšlennoje Strojitělstvo, vol. 10, pp. $46-50,1962$.

[17] M. Vild and M. Bajer, "Strengthening under load: the effect of preload magnitudes," Procedia Engineering, vol. 161, pp. 343348, 2016.

[18] CEN, "Eurocode 3: design of steel structures-part 1-1: general rules and rules for buildings," EN 1993-1-1:2005, 2009.

[19] S. R. O. Pontex, TP 42-Opravy, Obnovy a Přestavby Ocelových Nosných Konstrukcí Mostů, Ministerstvo dopravy, Praha, Czech Republic, 2014.

[20] R. V. Southwell, "On the analysis of experimental observations in problems of elastic stability," Proceedings of the Royal Society of London. Series A, vol. 135, no. 828, pp. 601-616, 1932.

[21] ANSYS $^{\circledR}$, Academic Research, Release 16.2, Help System, ANSYS Parametric Design Language Guide, ANSYS, 2015.

[22] M. Vild and M. Bajer, "Strengthening under load: experimental and numerical research," IOP Conference Series: Materials Science and Engineering, vol. 96, no. 1, pp. 1-10, 2015.

[23] L. Gannon, Y. Liu, N. Pegg, and M. Smith, "Effect of welding sequence on residual stress and distortion in flat-bar stiffened plates," Marine Structures, vol. 23, no. 3, pp. 385-404, 2010.

[24] O. W. Blodgett, Design of Welded Structures, James F. Lincoln Arc Welding Foundation, Cleveland, Ohio, USA, 1966.

[25] G. Huenersen, H. Haensch, and J. Augustyn, "Repair welding under load," Welding in the World, vol. 28, no. 9, pp. 174-182, 1990. 
[26] CEN, "Execution of steel and aluminium structures-part 2: technical requirements for steel structures," EN 1090-2+A1, 2011.

[27] Y. Liu and L. Gannon, "Experimental behavior and strength of steel beams strengthened while under load," Journal of Constructional Steel Research, vol. 65, no. 6, pp. 1346-1354, 2009.

[28] Y. Liu and L. Gannon, "Finite element study of steel beams reinforced while under load," Engineering Structures, vol. 31, no. 11, pp. 2630-2642, 2009.

[29] Y.-Q. Wang, L. Zong, R.-X. Zhu, X.-Y. Liu, and Y.-J. Shi, "Behavior of I-section steel beam welding reinforced while under load," Journal of Constructional Steel Research, vol. 106, pp. 278-288, 2015.

[30] A. Taras, J. P. Tapley, P. Kugler, and H. Unterweger, "On the stability behaviour and design of T-section beam-columns," in Proceedings of the 7th European Conference on Steel and Composite Structures (Eurosteel '14), 2014. 

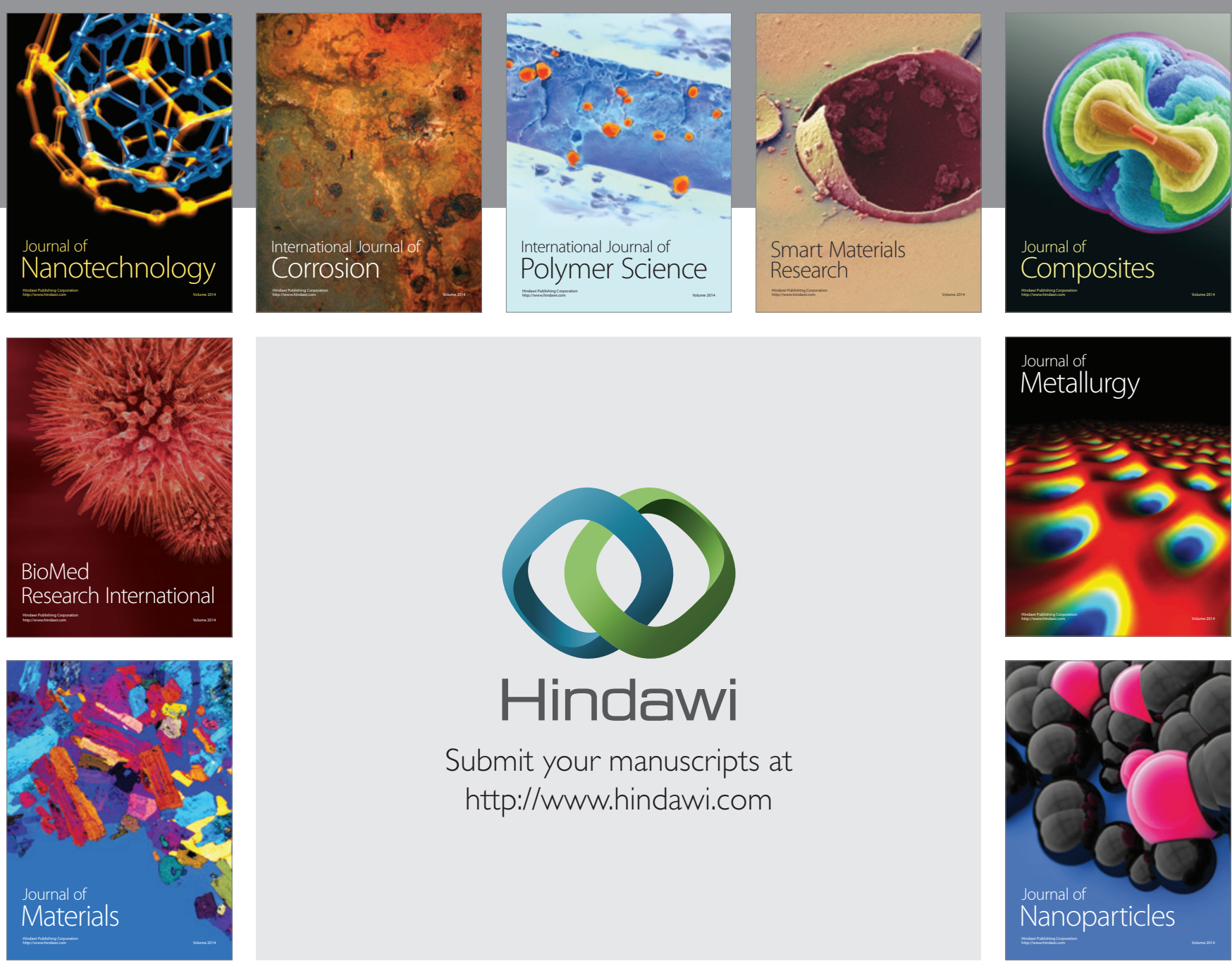

\section{Hindawi}

Submit your manuscripts at

http://www.hindawi.com

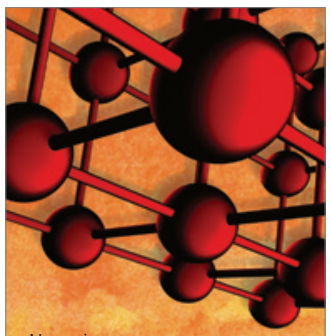

Materials Science and Engineering
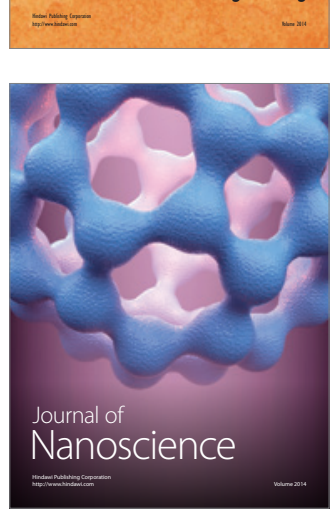
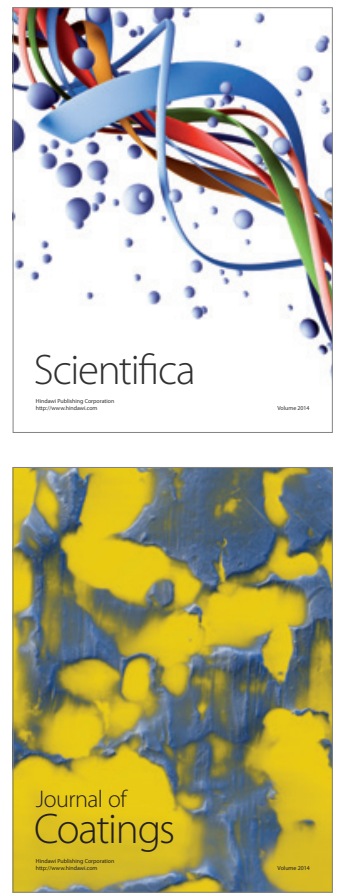


The Scientific World Journal
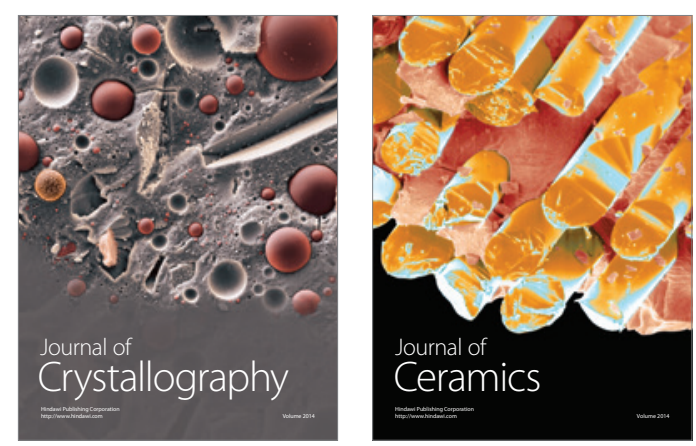
